Finance and Economics Discussion Series

Divisions of Research \& Statistics and Monetary Affairs

Federal Reserve Board, Washington, D.C.

\title{
Using Structural Shocks to Identify Models of Investment
}

\section{John M. Roberts}

2005-69

NOTE: Staff working papers in the Finance and Economics Discussion Series (FEDS) are preliminary materials circulated to stimulate discussion and critical comment. The analysis and conclusions set forth are those of the authors and do not indicate concurrence by other members of the research staff or the Board of Governors.

References in publications to the Finance and Economics Discussion Series (other than acknowledgement) should be cleared with the author(s) to protect the tentative character of these papers. 


\title{
Using Structural Shocks to Identify Models of Investment
}

\author{
John M. Roberts \\ Federal Reserve Board \\ October 2005
}

\begin{abstract}
This paper uses the response of investment to identified structural shocks to investigate some key issues, including the nature of adjustment costs and investment's responsiveness to user cost. In the estimation, the model parameters are chosen to match as closely as possible the impulse responses from an identified VAR. In the preferred results, both investment- and capital-stock adjustment costs are important; the size of the capital-stock adjustment costs is in line with estimates from firm-level studies; the investment-adjustment costs suggest rapid adjustment of investment to its desired level; and the estimated elasticity of substitution between capital and other inputs is considerably smaller than one. There is, however, an important sensitivity: The VAR's identified aggregate demand shock leads to a large crowding out effect-when output expands, investment falls. When this shock is included among those matched, the elasticity of substitution is near one and only investment adjustment costs are important.
\end{abstract}

The views expressed are those of the author and cannot be taken to represent those of the Board of Governors of the Federal Reserve System or other members of its staff. I am grateful to Per Berglund and Leanne Ussher for their efforts in organizing the volume for which this paper was prepared, to Per Berglund and Dave Reifschneider for helpful comments, and to Sean Taylor for help with the charts. 
In this paper, I use the response of aggregate investment to structural macroeconomic shocks in order to distinguish between some of the major competing models of investment. The two main modeling issues that will be addressed are the nature of adjustment costs and the responsiveness of investment to movements in user cost. The classic treatments of adjustment costs have focused on costs to adjusting the level of the capital stock (Lucas, 1967; Hayashi, 1982). A number of studies using firm-level data have provided empirical support for capital-stock adjustment costs; these studies have found that capital stock adjustment costs provide a useful characterization of investment dynamics (Gilchrist and Himmelberg, 1995; Cummins, Hassett, and Oliner, 1999). However, in macroeconomic data, investment is slow to respond to changes in its determinants. This sluggish adjustment suggests that investment adjustment costs likely also are present. Recently, Christiano, Eichenbaum, and Evans (2005) have estimated a macroeconomic model which includes only investment adjustment costs. Ultimately, which form of adjustment costs is more important is an empirical question; in the present paper, both are allowed to affect investment dynamics.

Another key modeling issue is the response of investment to movements in user cost. In his survey of the investment literature, Chirinko (1993) emphasized that a muted response of investment to changes in user cost relative to its response to other factors was one of the important stylized facts about investment. More recently, Tevlin and Whelan (2003) and Roberts (2003) have found such a muted response for U.S. non-high-tech equipment spending. Some firm-level studies have found that investment responds more strongly to movements in fundamental determinants of capital spending — such as sales and output - than to financial factors, such as the firm's share price (Gilchrist and Himmelberg, 1995, 1998; Cummins, Hassett, and Oliner, 1999). Chirinko, Fazzari, and Meyer (1999, 2005) have looked at the response of investment to nonfinancial determinants of user cost with firm-level data and also found a muted response to user cost. 
In the empirical work, the parameters of the investment model are chosen to match as closely as possible the impulse responses from an identified VAR. This estimation approach has been used in a number of recent macroeconomic studies, including Rotemberg and Woodford (1997), Amato and Laubach (2004), and Christiano, Eichenbaum, and Evans (2005). In an identified VAR, the shocks driving the economy are given a structural interpretation by imposing various short-run and long-run restrictions on the effects of the shocks. Ideally, these restrictions have strong justification in economic theory. In the VAR examined here, investment is included among the variables and so the response of investment to the structural shocks can be traced out.

A key advantage of this estimation approach is that we can choose which impulse responses to match. Thus, we can focus on the response of investment to those forces that have the highest credibility as structural factors. For example, Rotemberg and Woodford (1997) and Christiano, Eichenbaum, and Evans (2005) argue that identified monetary policy shocks have a particularly high degree of credibility as structural shocks, both because of confidence in the assumptions used to identify them and because such shocks have been the subject of considerable scrutiny. Altig, Christiano, Eichenbaum, and Linde (2005) make similar claims for identified technology shocks: Technology shocks have been extensively studied, and we can be confident in the assumptions needed to identify them.

Another advantage of the impulse-response matching estimation approach is that it avoids complications stemming from reverse causation that have been a concern in the investment literature. Under the reverse-causation conjecture, interest rates are often low because of weak investment, which leads to a spurious correlation between low interest rates and low investment (see Chirinko, 1993, for a discussion). By excluding the effects of the investment shock from the impulse responses that are matched, we can avoid the problem of reverse causation.

In this study, I will focus on explaining U.S. business spending on equipment other than information technology. This category excludes expenditures on structures and on the high-tech categories of computers, software, and communications equipment from overall business fixed investment. I focus on this narrower category for two reasons. First, the excluded categories have important idiosyncrasies: For 
structures, depreciation is much lower than for equipment and the lag in response to changes in its determinants appears to be considerably longer than for equipment spending (Edge, 2000). For information technology, depreciation is much faster than for other types of equipment; furthermore, changes in relative prices appear to be a much more important determinant than for other forms of equipment (Tevlin and Whelan, 2003). The second reason is that ratios of spending in the excluded categories to business-sector output have shifted over time, with the share of structures falling and the share of information technology rising. By contrast, the share of non-high-tech equipment has been more stable. While non-high-tech equipment is a narrow category, over the 1965-2002 period, it was about half of overall business fixed investment spending.

The structure of the paper is as follows. Section one derives the model of investment dynamics. Section two presents the estimates of the structural VAR. Section three presents the estimates of the investment model. Section four presents additional discussion of the elasticity of substitution and section five, conclusions.

\section{The Investment Model}

The firm is assumed to choose investment and labor input to maximize profits, subject to a production function and a capital accumulation equation. The production function reflects costs to adjusting the level of the capital stock and the rate of investment. The adjustment costs are thus incurred by the firm and deducted directly from output.

$$
\begin{gathered}
\operatorname{Max}_{\{H, K, I\}} \sum_{t=0}^{\infty}\left[\prod_{s=0}^{t}\left(1+r_{s}\right)^{-1}\right]\left\{Y_{t}-W_{t} H_{t}-I_{t}\right. \\
\left.-\Lambda_{t}\left[K_{t+1}-I_{t}-(1-\delta) K_{t}\right]\right\}
\end{gathered}
$$

where,

$$
Y_{t}=F\left(K_{t}, A_{t} H_{t}\right)-\frac{\gamma_{1}}{2}\left(\frac{I_{t}}{K_{t-1}}-\delta-g\right)^{2} K_{t}-\frac{\gamma_{2}}{2}\left(\frac{\Delta I_{t}}{I_{t-1}}-g\right)^{2} I_{t}
$$

$Y$ is output, $H$ is total worker hours, $W$ is the wage, $K$ is the capital stock, $I$ is investment, $\delta$ is the depreciation rate of the capital stock, $r$ is the required return on 
capital, $A$ is an index of (labor-augmenting) technical progress, and $g$ is the economy's average growth rate.

The first-order conditions for investment and the capital stock can be written as:

$$
\begin{aligned}
\Lambda_{t} & =1+\gamma_{1} \frac{K_{t}}{K_{t-1}}\left(\frac{I_{t}}{K_{t-1}}-\delta-g\right) \\
& +\gamma_{2} \frac{I_{t}}{I_{t-1}}\left(\frac{\Delta I_{t}}{I_{t-1}}-g\right) \\
& -\gamma_{2} \frac{1}{1+r_{t+1}} \frac{I_{t+1}}{I_{t}} \frac{\Delta I_{t+1}}{I_{t}}\left(\frac{\Delta I_{t+1}}{I_{t}}-g\right) \\
& +\frac{\gamma_{2}}{2}\left(\frac{\Delta I_{t+1}}{I_{t}}-g\right)^{2} \\
F_{K t}= & \Lambda_{t-1}\left(1+r_{t}\right)-(1-\delta) \Lambda_{t}
\end{aligned}
$$

Equation 4 is the familiar relationship between the shadow price of the capital stock, $\Lambda$, and the present-discounted value of future marginal product of capital. In equation 3, when there are only capital-stock adjustment costs $\left(\gamma_{2}=0\right)$, it becomes the familiar relationship between investment and the shadow price of the capital stock. Alternatively, when there are only investment adjustment costs $\left(\gamma_{1}=0\right)$, the shadow price of capital continues to be crucial to investment dynamics, but the relationship now involves the change in investment rather than the level.

Looking ahead to the estimation, we now modify equations 3 and 4 by taking a log-linear approximation and assuming that $F$ has a constant-elasticity-ofsubstitution form:

$$
\begin{aligned}
\lambda_{t}= & \gamma_{1}(1+g)\left(\Delta k_{t}-g\right) \\
& +\gamma_{2}(1+g)\left[\left(\Delta i_{t}-g\right)-\frac{g}{1+\bar{r}}\left(\Delta i_{t+1}-g\right)\right] \\
\sigma^{-1}\left(y_{t}-k_{t}\right)= & \frac{1+\bar{r}}{\bar{r}+\delta}\left(\lambda_{t-1}+r_{t}\right)-\frac{1-\delta}{\bar{r}+\delta} \lambda_{t}
\end{aligned}
$$


where lower-case letters represent logs of their upper-case counterparts, $\bar{r}$ is the long-run average value of $r_{t}, \sigma$ is the elasticity of substitution between capital and labor input, and the approximations $\Delta i_{t} \equiv\left(I_{t}-I_{t-1}\right) / I_{t-1}$ and $\Delta k_{t} \equiv I_{t-1} / K_{t-1}-\delta$ have been used.

Some additional manipulation may help make the structure of the model more transparent:

$$
\begin{aligned}
\left(\Delta i_{t}-g\right)= & \frac{1}{\gamma_{2}}\left[\frac{1}{1+g} \lambda_{t}-\gamma_{1}\left(\Delta k_{t}-g\right)\right] \\
& +\frac{g}{1+\bar{r}} E_{t}\left(\Delta i_{t+1}-g\right) \\
\lambda_{t}= & \frac{1-\delta}{1+\bar{r}} E_{t} \lambda_{t+1}+\frac{\bar{r}+\delta}{1+\bar{r}} \sigma^{-1}\left(y_{t+1}-k_{t+1}\right)-r_{t+1} .
\end{aligned}
$$

Finally, the log-linearized capital accumulation equation is also needed to complete the model:

$$
\Delta k_{t}=\frac{g+\delta}{1+g}\left(i_{t-1}-k_{t-1}\right)
$$

\section{The Structural VAR}

\subsection{The data}

The structural VAR includes five variables: Investment is measured as the change in $\log$ of the stock of non-high-tech equipment multiplied by 100 to make the units comparable to percent changes. The change in the log of the capital stock is, of course, approximately equal to net investment divided by the (lagged) capital stock. Output relates to the business sector and also enters the model as the log difference multiplied by 100 . Hours are for the nonfarm business sector; they are detrended as described below and measured as 100 times the log deviation from trend. Inflation is 400 times the log difference in the personal consumption expenditures deflator. And the federal funds rate is introduced in percent per annum. 
Hours are detrended by running the Hodrick-Prescott filter through the log of hours relative to the working-age population, using an HP filter coefficient of 64,000 . The hours trend is also taken out of output and the equipment stock prior to log differencing. The data are quarterly, consistent with the frequency of the published investment, output, and hours data. The estimation period is 1965 to 2002.

The detrending procedure removes a trend from hours prior to estimation while implicitly allowing a stochastic trend to remain in productivity. One reason for this choice is that while shocks to trend productivity are frequently posited as an important source of business-cycle variation, shocks to trend labor supply are a less frequent object of inquiry. Another reason is that when per capita hours are allowed to follow a stochastic trend, the variance of that trend is estimated to be considerably smaller than that of productivity: For example, in an examination of stochastic trends in hours and productivity using state-space methods, Roberts (2001) finds that the variance of the productivity trend is about four times larger than the variance of the hours trend. This result suggests that the focus of the literature on the implications of shocks to trend productivity rather than to trend hours is appropriate.

\subsection{The identification scheme}

In identifying the structural shocks, I mostly rely on short-run restrictions; as Christiano, Eichenbaum, and Vigfusson (2005) have recently emphasized, short-run restrictions have better statistical properties in small samples than do long-run restrictions. I do, however, use one long-run restriction to identify a technology shock.

I assume that investment is not affected by current-period information about other variables. Given that planning lags in investment are likely important, this seems a safe assumption (see Edge, 2000, for a discussion). On the other hand, investment is allowed to affect the other variables in the model contemporaneously. Given that investment is, mechanically, a component of aggregate spending, this assumption also seems reasonable. At the other extreme, the federal funds rate is assumed to be affected by all of the other variables in the model in current period, but is assumed not to affect any of the other variables. The assumptions about the funds rate are similar to those used by Christiano, Eichenbaum, and Evans $(1999,2005)$ to identify a shock to monetary policy. Briefly, the economic logic underlying these 
assumptions is that the central bank is well-informed about current-quarter economic activity and inflation, but the private sector takes time to react to changes in monetary policy. The investment planning lags just discussed are one example of the behavior underlying such decision lags.

Inflation is allowed to be affected by current-period economic activity (hours and output) but not by monetary policy. While firms are likely to be aware of current market conditions for their own products, they have less incentive to monitor monetary-policy developments, leading to lags in the impact of monetary policy on inflation relative to the impact of hours and output. While inflation is assumed to be affected by economic activity contemporaneously, it is not allowed to affect activity in the current period.

The restrictions discussed so far permit the identification of three structural shocks - to investment, inflation, and monetary policy. Yet to be disentangled are the shocks to the output and hours equations. In this case, there are likely many shocks that would affect both output and hours simultaneously: Shocks to aggregate demand would likely raise both, for example; productivity shocks could also affect both variables contemporaneously. One important productivity shock, however, can be identified by its long-run consequences: Technology shocks can reasonably be assumed to be the only shocks that will affect output per hour in the long run. I therefore impose the restriction that of the two remaining structural shocks, only one affects output in the long run; the other is restricted to have only temporary effects on output.

As mentioned in the introduction, the shocks to monetary policy and technology can be viewed as having the highest degree of credibility among the shocks identified here: These shocks have been widely discussed in the macroeconomic literature and the assumptions underlying them are plausible. At the other extreme, for the purposes of identifying investment models, the investment shock is the least helpful: Given concerns about reverse causation, estimates based on it could be misleading. In between are the IS and inflation shocks. These shocks have received less attention than the first two. While the assumptions used to identify them can be defended on economic grounds, there is less of a consensus surrounding these shocks and their effects. 
The equations for investment, inflation, and the federal funds rate can be estimated with ordinary least squares. I estimate the equations for hours and output using the instrumental variables approach of Shapiro and Watson (1989), modified to account for the fact that investment is exogenous to hours and output.

\subsection{VAR results}

Figure 1 shows impulse responses from the structural VAR, along with a 90 percent confidence band. I discuss the VAR results organized by the impulse responses to each shock, taken in order of the degree of credibility of the identification as discussed in the previous subsection.

\subsubsection{MONETARY-POLICY SHOCK}

The effects of the identified monetary policy shock are similar to those found in earlier work: A shock to monetary policy that raises the federal funds rate leads to a reduction in output and labor input within a few quarters. Output remains below its baseline value for about three years, and the effect is statistically significant for about half that time. Hours follow a similar pattern. Consistent with the phenomenon of procyclical labor productivity, output falls more in percentage terms than do hours.

Inflation initially rises following the monetary-policy shock - the well-known "price puzzle." Within four quarters, however, inflation is below its baseline level. Inflation remains low for an extended period thereafter.

The monetary-policy shock also leads to a drop in investment. In the model of section 1, the shadow price of capital is the key determinant of investment. The monetary-policy shock affects the shadow price of capital through two channels. One is through higher interest rates, which reduce the shadow price of capital by leading to a steeper discounting of future dividends. In the other, the drop in output implies a lower marginal product of capital, and thus lower dividends, both now and in the future and thereby pushes down the shadow price of capital. As can be seen in equation 8 , the parameter $\sigma$ determines the relative strength of these two channels.

\subsubsection{TECHNOLOGY SHOCK}

The technology shock has an immediate positive effect on output. Output then rises somewhat more before edging down to a level about the same as that immediately 
following the shock. Hours initially fall somewhat in response to the trend productivity shock. However, within four quarters, hours are above their baseline level. Investment also responds (with a lag) to the trend productivity shock. As might be expected, a permanent improvement in productivity leads to new investment opportunities and thus higher investment.

Figure 1

Impulse Responses in Identified VAR
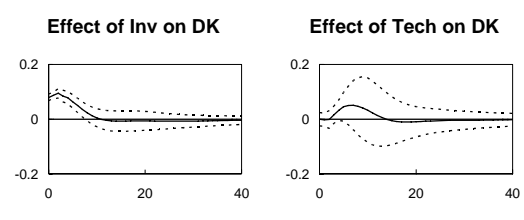

Effect of IS on DK

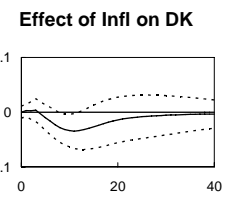

Effect of MP on DK

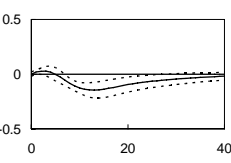

Effect of IS on $Y$

Effect of Infl on $Y$

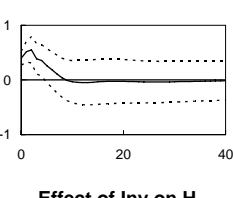

Effect of Tech on $Y$
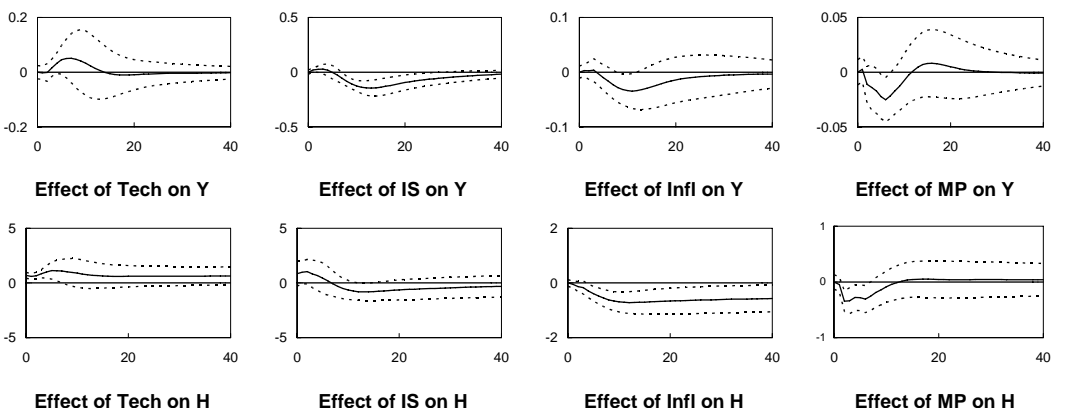

Effect of IS on $\mathrm{H}$

Effect of Infl on $\mathrm{H}$
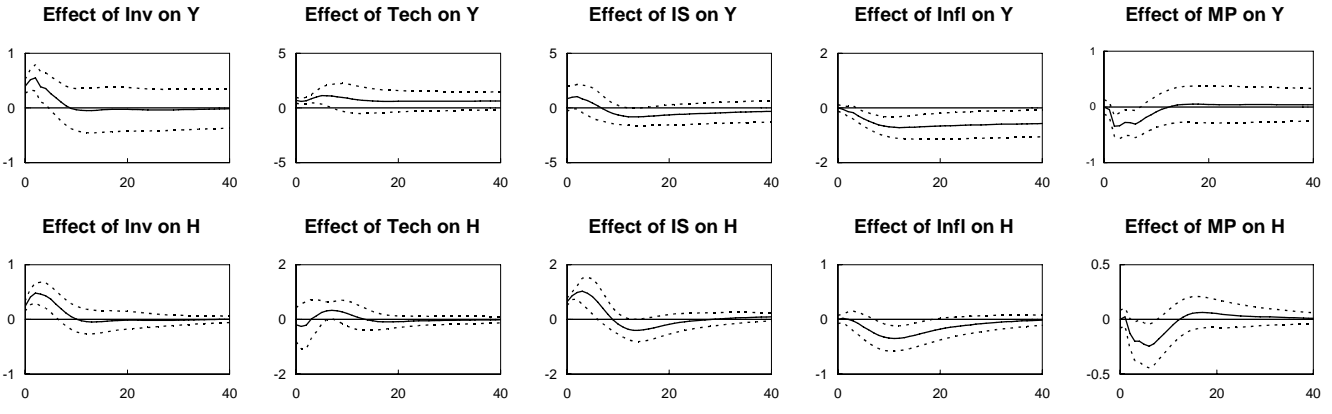

Effect of MP on $\mathrm{H}$

Effect of Inv on DP

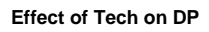

Effect of IS on DP

Effect of Infl on DP
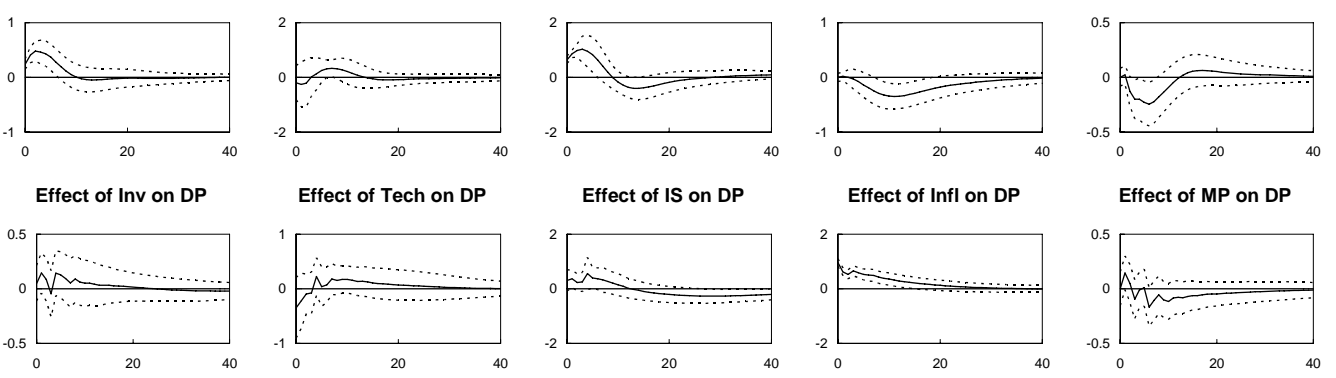

Effect of MP on DP

Effect of Inv on RFF

Effect of Tech on RFF

Effect of IS on RFF

Effect of Infl on RFF
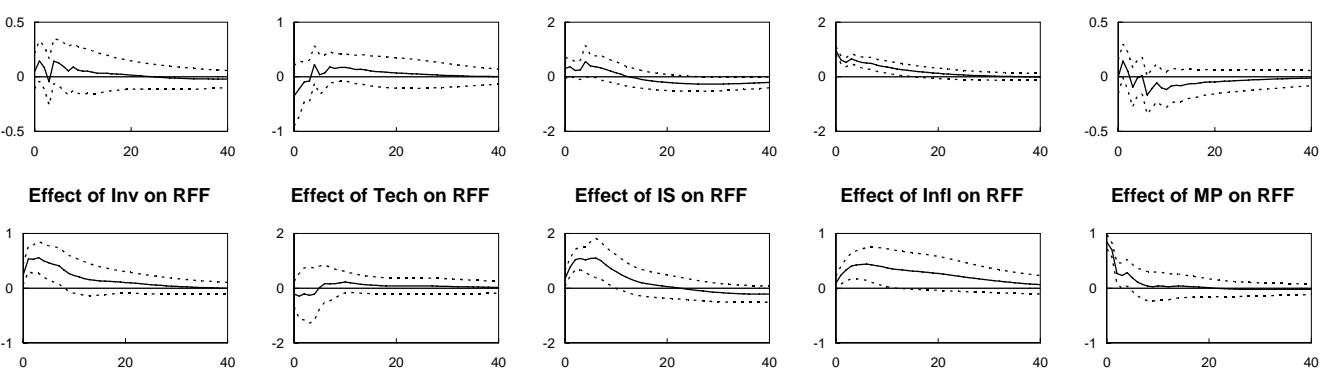

Notes: Dotted lines depict 90 percent confidence intervals.

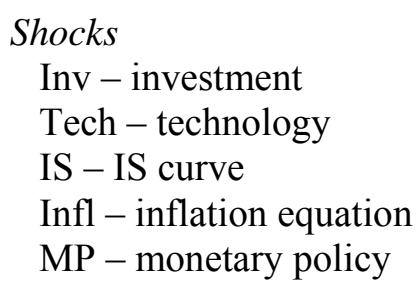

Shocks

Inv - investment

Tech - technology

IS - IS curve

Infl - inflation equation

\section{Variables}

DK - investment

$\mathrm{Y}$ - output

$\mathrm{H}$ - hours

DP - inflation

$\mathrm{RFF}$ - federal funds rate 
One interpretation of the hump-shaped response of output, hours, and investment to the trend productivity shock is that the increase in trend productivity initially stimulates aggregate demand somewhat more than it raises aggregate supply. This interpretation is confirmed by the pattern of responses for inflation. The boost to productivity initially pushes down inflation: If wages are sticky, we might expect a rise in productivity to reduce costs and thus inflation. Eventually, however, inflation rises above its baseline level, consistent with the notion that excess aggregate demand raises inflation as it boosts output and hours beyond their equilibrium levels.

The initial effect of the trend productivity shock on the federal funds rate is negative. This response might be expected in a monetary-policy reaction function in which the central bank is responding to the initial drop in hours and inflation. Once hours and inflation exceed their baseline values, however, so does the funds rate.

One disappointing aspect of the technology shock is that its effects are not estimated precisely. While the initial effect of the shock on output is statistically significant, the confidence bands widen considerably thereafter, and within a few years after the initial shock, the effect is no longer significant. None of the effects on the other variables is ever statistically significant. Notably, beyond the first few quarters, the estimated effects of the trend productivity shock on investment have very wide confidence bands. Preliminary attempts to sharpen the estimates - for example, by reducing the number of lags included in the VAR from four to three-were unsuccessful. The question of how to sharpen these estimates will be revisited in the conclusion. The imprecision of these estimates will limit the ability to make useful inferences based on the response of investment to technology shocks.

\subsubsection{INFLATION SHOCK}

The inflation shock has a persistent effect on inflation itself. The shock also leads to statistically significant declines in hours, output, and investment, with the effects reaching a peak about three or four years after the initial shock. The federal funds rate rises subsequent to the shock, consistent with the view that tight monetary policy may be responsible for some of the subsequent weakness in real economic activity.

The effect of the inflation shock on output is highly persistent. Indeed, the depressing effect is statistically significant at the 90 percent level even after ten years. 
This highly persistent effect was not ruled out in the estimation - only the IS shock was restricted from having a permanent effect on output. Thus, one interpretation of the inflation shock is that it represents an additional supply shock that has a permanent (depressing) effect on output.

\subsubsection{IS SHOCK}

The technology shock was identified through a long-run restriction on the shocks to the hours and output shocks equations. We might expect that the complement to the productivity shock would be an aggregate demand shock. The impulse responses to this shock bear out this prediction: The shock initially raises hours, output, and inflation. Because the effects of monetary policy have been accounted for separately, it seems reasonable to associate this shock with the textbook "IS" shock.

The shock leads to an increase in the federal funds rate, consistent with the notion that countercyclical monetary policy should act to offset demand shocks. The increase in the funds rate is highly statistically significant, and durable: The funds rate remains significantly above its initial level in a statistical sense for several years, and the point estimate does not return to its initial level until about five years after the initial shock. Given the strong reaction of monetary policy to the shock, it is perhaps not surprising that both hours and output drop below their baseline levels within eight to ten quarters after the initial shock; with a lag, inflation follows.

By assumption, the IS shock has no permanent effect on output. As can be seen, however, after its decline, output returns to its baseline value only very gradually. Still, after about six years, the effect is well within the 90 percent confidence band.

Investment initially rises a bit in response to the shock, but begins to drop a few quarters later. Investment remains significantly below its baseline value for a considerable period following the initial shock. One possible explanation for the investment decline is that there is an important interest-rate effect on investment: A surge in aggregate demand that originates outside the investment sector leads to higher interest rates and these higher interest rates, in turn, lead to lower investment. Thus, by pushing up interest rates, the IS shock may have an important "crowding out" effect on investment. This crowding-out effect is precisely estimated and so will have an important effect in the structural estimation. 


\subsubsection{INVESTMENT SHOCK}

Because of concerns over reverse causation, the shock to the investment equation will not be used in the estimation. Still, for completeness, it is worth noting some of its properties. The shock leads to a persistent increase in investment. The effect is initially slightly hump-shaped; investment returns to baseline within three years after the initial shock. The shock to investment also leads to an increase in output. That is perhaps not surprising because investment is one of the components that go into the expenditure-side adding up of output. The investment shock also leads to an increase in hours, an effect that is strongly statistically significant and follows closely the movements in output and investment. The hours effects suggest that the investment shock is indeed capturing an authentic economic phenomenon and is not simply measurement error.

Inflation rises somewhat in the wake of the investment shock, although the effect is not statistically significant. The federal funds rate also increases; this rise is statistically significant. An interpretation of this increase is that monetary policy tightens as hours and output exceed their baseline values. This rise in interest rates following an exogenous increase in investment is symptomatic of reverse causation, as this shock leads simultaneously to high investment and high interest rates.

\section{Estimation}

\subsection{Estimation approach}

I estimate the model by choosing the structural parameters $-\gamma_{1}, \gamma_{2}$, and $\sigma-$ so as to make the impulse responses from the structural model match as closely as possible to those from the VAR. As noted earlier, this approach is similar to that used by, for example, Rotemberg and Woodford (1997), Amato and Laubach (2004), and Christiano, Eichenbaum, and Evans (2005). One important difference between the current application and these others, however, is that while they were choosing the parameters of all of the equations in the model, here, reduced-form specifications are used for the variables other than investment. In particular, I use the same specifications that were used in the reduced-form VAR, holding the coefficients fixed.

One advantage of this approach is that it is more robust to the possibility of 
misspecification in the non-investment parts of the model. As we saw in the previous section, however, one drawback of the approach is the imprecision of the estimated VAR impulse responses.

A minimum-distance procedure is used, in which the structural parameters are chosen to minimize the weighted squared deviations of the structural model impulse responses from the responses of investment to the identified shocks in the VAR. The first twenty periods of the impulse-response function (IRF) are matched. The sum of squared deviations corrects for correlation across the individual impulse responses. In particular, a quadratic form is minimized, with the weighting matrix equal to an estimate of the inverse of the covariance matrix of the VAR impulse responses; the estimate of the covariance matrix is obtained from stochastic simulation of the VAR model. The minimized distance function can be used to test whether the structuralmodel impulse responses are significantly different from the VAR IRFs. Two times this quantity will have a $\chi^{2}$ distribution, with degrees of freedom equal to the difference between the number of impulse responses to be matched and the number of parameters in the structural model: The larger the value of the quadratic form, the greater the distance between the structural and VAR impulse responses and thus the greater the chance that the impulse responses are significantly different. The minimum-distance criterion can also be used to test for the statistical significance of the difference between two (nested) sets of estimates.

\subsection{Calibrating long-run averages}

The variable $r_{t}$ in the structural model is the required return on capital, whereas the VAR includes the federal funds rate, which is a risk-free interest rate. These variables

will differ by a risk premium (as well as by expected inflation). If we assume a constant risk premium, then $r_{t}$ moves one-for-one with changes in the real federal funds rate:

$$
r_{t}=\text { premium }+r f f_{t}-E_{t} d p_{t+1} \text {, }
$$

where $r f f$ is the federal funds rate and $E_{t} d p_{t+1}$ is the expected inflation rate. The average net return on capital ( $\bar{r}$ in equations 5 through 8 ) is assumed to be 8 percent, 
a value that is consistent with the average capital share in the business sector. Over the 1965-2002 period, the real federal funds rate averaged 3.2 percent, so the premium is about 5 percent.

Two other parameters are calibrated: The average depreciation rate for nonhigh-tech equipment, $\delta$, was 12 percent per year over the 1965-2002 period. And $g$, the average growth rate of business-sector labor productivity, was 2 percent per year over this period.

\subsection{Results}

Table 1 presents results using only the monetary-policy shock to identify the model. In column 1 , the elasticity of substitution between capital and labor input, $\sigma$, is constrained to be one; the adjustment cost parameters $\gamma_{1}$ and $\gamma_{2}$ are freely estimated. Both of the adjustment-cost parameters are statistically significant at the 10 percent confidence level (although not at the 5 percent level). The point estimates are quite reasonable: For the capital stock, they imply that, in the absence of investment adjustment costs, the stock adjusts at an annual rate of 23 percent toward the target stock. For investment, the estimates imply that investment adjusts about 28 percent per quarter toward its implicit target level. This adjustment speed is consistent with the evidence on firm planning lags discussed in Edge (2000).

These results are similar to those of Roberts (2003). As discussed there, this pace of capital-stock adjustment is similar to that found in firm-level studies of investment dynamics. The implicit investment adjustment speed suggests that investment moves rapidly toward the path dictated by the adjustment of the capital stock. As can be seen in the dashed line in figure 2, these structural estimates imply impulse responses that are consistent with the hump-shaped response of investment to a monetary-policy shock reflected in the VAR.

\footnotetext{
1 The capital-stock adjustment speed is computed by setting $\gamma_{2}$ to zero in equation 5 , using this expression to substitute for $\lambda_{t}$ into equation 6 , and then solving for the roots of the resulting quadratic equation in $k_{t}$. For the investment adjustment speed, equation 9 is used to replace $\Delta k_{t}$ in equation 5 with $i_{t}$. We then have a simple dynamic equation in investment, with the implicit target investment rate proportional to $\lambda_{t}$.
} 
Table 1

Estimates of Structural Investment Model Based on matching monetary-policy IRF only

\begin{tabular}{lccc}
\hline & $(1)$ & $(2)$ & $(3)$ \\
\hline$\gamma_{1}$ & 49.8 & 0.0 & 30.0 \\
& $(27.6)$ & -- & -- \\
$\gamma_{2}$ & 5.3 & 9.0 & 5.0 \\
$\sigma$ & $(2.7)$ & $(3.6)$ & $(2.2)$ \\
& 1.0 & 1.0 & 1.0 \\
Minimum distance & -- & -- & -- \\
criterion & 2.7 & 9.1 & 3.3 \\
$\begin{array}{l}\text { Adjustment speeds: } \\
\text { Capital stock }\end{array}$ & & & \\
Investment & $23 \% \mathrm{AR}$ & n.a. & $25 \% \mathrm{AR}$ \\
& $28 \% \mathrm{QR}$ & & $30 \% \mathrm{QR}$ \\
\hline
\end{tabular}

Notes: Numbers in parentheses are standard errors.

-- indicates constrained parameter.

IRF-impulse response function.

$\mathrm{AR}$ - annual rate.

$\mathrm{QR}$ - quarterly rate.

n.a.- not applicable.

In column 2, the restriction $\gamma_{1}=0$ is imposed, so that there are only investment adjustment costs. This restriction was also imposed by Christiano, Eichenbaum, and Evans (CEE, 2005). With this restriction, investment is estimated to be much more costly to adjust than in the unconstrained case. ${ }^{2} \gamma_{2}$ is now statistically significant at the 5 percent level. Although $\gamma_{1}$ was not highly statistically significant in column 1 , imposing the restriction that $\gamma_{1}=0$ is strongly rejected, as the minimum distance criterion rises from 2.7 to 9.1 . The estimate of $\gamma_{2}$ in column $2-9.0-$ is about three times larger than that reported by CEE. There are a number of differences between this analysis and CEE's. One potentially important difference is that CEE look at a broad measure of investment while here, investment is restricted to non-high-tech equipment.

\footnotetext{
${ }^{2}$ It is not possible to infer an investment adjustment speed based on the estimates in column 2: With $\gamma_{1}=0$, the capital stock is assumed to be costless to adjust and there is thus no well-defined target investment rate.
} 
Figure 2

Response of Investment to Monetary-Policy Shock

Comparison of VAR and Structural Model Responses

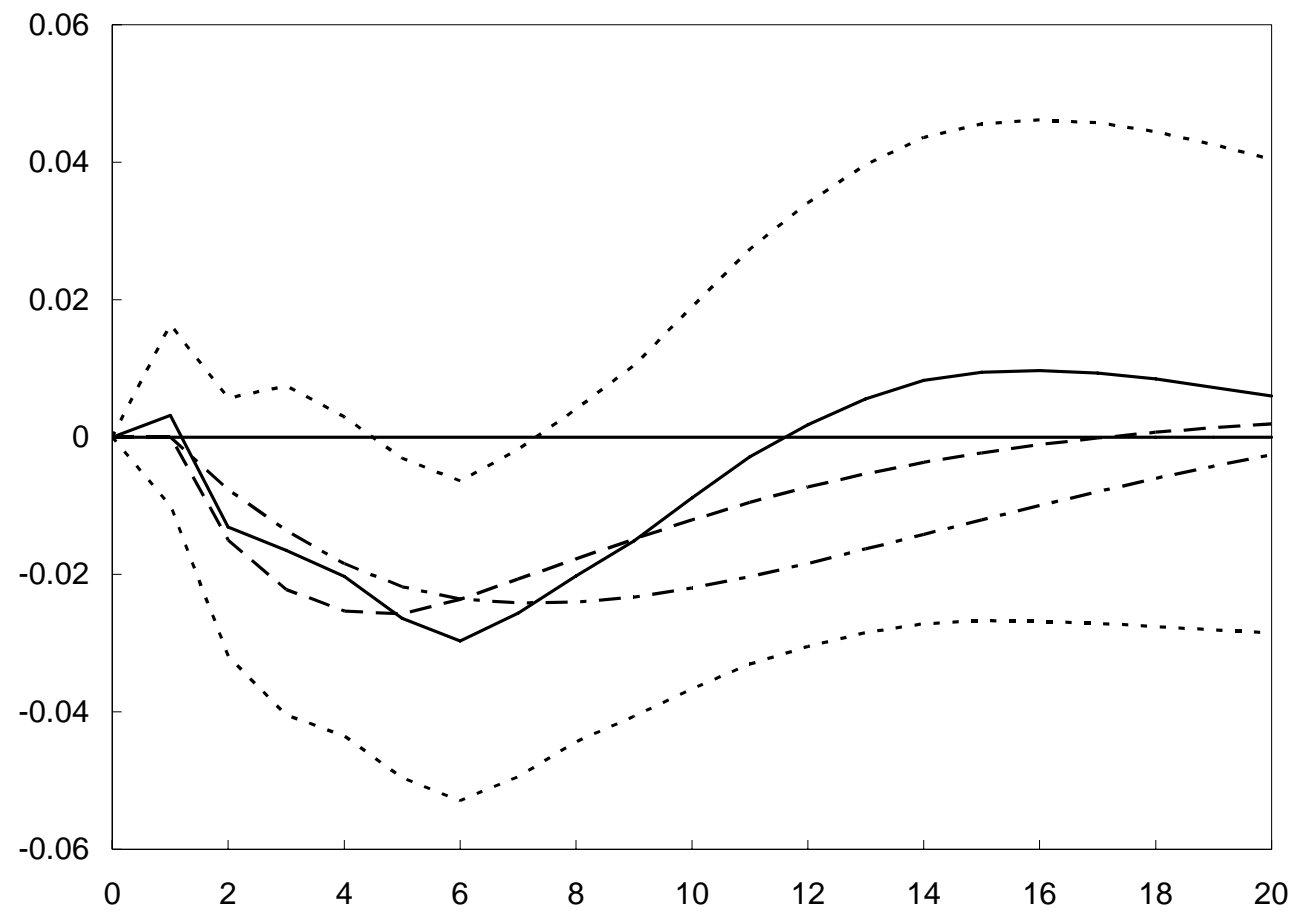

Notes: Responses to unit shocks

Solid: VAR impulse response

Dotted: 90 percent confidence interval around VAR impulse response

Dashed: Allows both investment and capital stock adjustment costs

Dot-dash: Investment adjustment costs only

$\sigma=1$ imposed

Figure 2 also shows the IRF with the $\gamma_{1}=0$ restriction imposed. In the first eight quarters following the shock, both models well approximate the shape of the VAR impulse response. After that, however, the model with investment adjustment costs only implies much more persistence in investment than in the VAR IRF. In the model that allows for capital-stock adjustment costs, investment returns to its baseline level more rapidly and thus captures the VAR impulse response better.

In the final column of table $1, \gamma_{1}$ is set equal to 30 . This value is chosen to be consistent with a capital-stock adjustment speed of 25 percent at an annual rate, in 
line with the firm-level evidence summarized in Roberts (2003). As can be seen, the overall fit of the model is little changed with this restriction. ${ }^{3}$

In table 2 , the model is estimated by fitting only the impulse responses to the technology shock. In column 1 , the estimated value of $\gamma_{1}$ is pushed to its theoretical minimum of zero. The estimate of $\gamma_{2}$ is small relative to the values in table 1 , but it is not precisely estimated. In column $2, \gamma_{1}$ is set equal to 30 , consistent with moderate capital-stock adjustment costs. The fit of the model deteriorates somewhat; the point estimate of $\gamma_{2}$ is larger, but it remains statistically insignificant. Overall, these results suggest that, by itself, the technology shock gives little guidance as to the values of the parameters of the model.

Table 2

Estimates of Structural Investment Model Based on matching technology IRF only

\begin{tabular}{lcc}
\hline & $(1)$ & $(2)$ \\
\hline$\gamma_{1}$ & 0.0 & 30.0 \\
$\gamma_{2}$ & -- & -- \\
& 1.7 & 3.3 \\
$\sigma$ & $(1.5)$ & $(3.4)$ \\
& 1.0 & 1.0 \\
$\begin{array}{l}\text { Minimum distance } \\
\text { criterion }\end{array}$ & -- & -- \\
\hline
\end{tabular}

Notes: See table 1.

Table 3 presents estimates based on fitting both the monetary-policy and technology impulse-response functions. In the first column, $\sigma$ is constrained to be one, as in the earlier estimation. Relative to the estimation based on monetary-policy shocks alone, the point estimates are little changed; they are a bit more precise, however. In column 2 , the $\sigma=1$ restriction is relaxed. The resulting point estimate of $\sigma$ is quite small - around 0.1. Allowing free estimation of $\sigma$ improves the fit of the model considerably; put another way, we can strongly reject the hypothesis that

\footnotetext{
${ }^{3}$ Although the value of $\gamma_{1}$ in column 3 is 40 percent smaller than the value in column 1 , the implicit capital-stock adjustment speed is only about 8 percent higher, reflecting the strongly nonlinear relationship between the adjustment-cost parameters and the adjustment speeds.
} 
$\sigma=1$. The estimate of $\gamma_{2}$ is now somewhat larger than in column 1 , but it still implies that investment moves rapidly toward its target level. The estimate of $\gamma_{1}$ in column 2 is rather imprecise, although it is close to the moderate benchmark value of 30. In columns 3 and $4, \gamma_{1}$ is constrained to be 30 and 0 , respectively. As can be seen, neither restriction has much effect on the fit of the model, consistent with the small $t$ ratio for $\gamma_{1}$.

Table 3

Estimates of Structural Investment Model Based on matching both monetary-policy and technology IRFs

\begin{tabular}{lcccc}
\hline & $(1)$ & $(2)$ & $(3)$ & $(4)$ \\
\hline$\gamma_{1}$ & 41.6 & 24.5 & 30.0 & 0.0 \\
& $(23.0)$ & $(27.7)$ & -- & -- \\
$\gamma_{2}$ & 4.7 & 7.8 & 7.7 & 10.2 \\
& $(2.1)$ & $(4.3)$ & $(4.2)$ & $(4.8)$ \\
$\sigma$ & 1.0 & .07 & .07 & .05 \\
& -- & $(.05)$ & $(.05)$ & $(.03)$ \\
Minimum distance & 6.6 & 2.9 & 3.0 & 3.8 \\
criterion & & & & \\
$\begin{array}{l}\text { Adjustment speeds: } \\
\text { Capital stock }\end{array}$ & $24 \% \mathrm{AR}$ & $26 \% \mathrm{AR}$ & $25 \% \mathrm{AR}$ & n.a. \\
\multicolumn{1}{l}{ Investment } & $44 \% \mathrm{QR}$ & $16 \% \mathrm{QR}$ & $19 \% \mathrm{QR}$ & \\
& & & & \\
\hline
\end{tabular}

Notes: See table 1.

Figure 3 compares the impulse responses with and without the restriction $\sigma=1$ imposed. Both specifications capture the VAR response to a monetary-policy shock about equally well, but the specification with a smaller value of $\sigma$ allows the model to do a better job approximating the response to the technology shock.

Table 4 presents results with the inflation shock added to the set of IRFs to be matched. Relative to the estimates in column 2 of table 3 , the estimate of $\gamma_{1}$ is more precise and is now statistically significant at the 5 percent level. The point estimate of $\sigma$ remains well less than one, but it is higher than before and its difference from one is no longer statistically significant. The capital-stock adjustment speed is 24 percent at an annual rate, similar to earlier estimates. The investment adjustment speed is quite high, also in line with earlier results. 
Figure 3

\section{Response of Investment to Technology and Monetary-Policy Shocks \\ Comparison of VAR and Structural Model Responses}

Technology shock

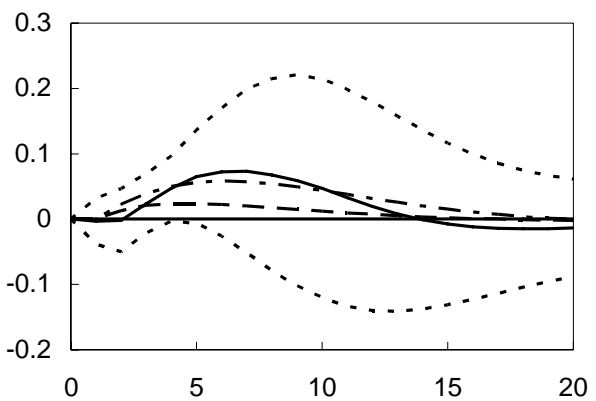

Monetary-policy shock

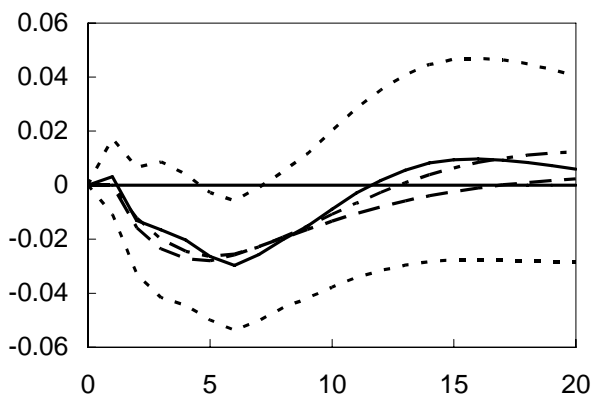

Notes: Responses to unit shocks

Solid line: VAR impulse response

Dotted: 90 percent confidence interval around VAR impulse response

Dashed: $\sigma=1$ imposed

Dot-dash: $\sigma$ is freely estimated

Both allow investment and capital stock adjustment costs

Table 4

\section{Estimates of Structural Investment Model}

Based on matching monetary-policy, technology, and inflation IRFs

\begin{tabular}{|c|c|c|c|c|c|}
\hline & (1) & (2) & (3) & (4) & (5) \\
\hline \multirow[t]{2}{*}{$\gamma_{1}$} & 39.0 & 30.0 & 0.0 & 39.5 & 59.2 \\
\hline & (19.4) & -- & -- & $(18.2)$ & $(40.8)$ \\
\hline \multirow[t]{2}{*}{$\gamma_{2}$} & 5.7 & 5.5 & 9.8 & 4.9 & 15.7 \\
\hline & (2.9) & (2.6) & $(4.0)$ & $(2.0)$ & $(5.2)$ \\
\hline \multirow[t]{2}{*}{$\sigma$} & .40 & .38 & .17 & 1.0 & .07 \\
\hline & $(.48)$ & $(.41)$ & $(.10)$ & -- & -- \\
\hline $\begin{array}{l}\text { Minimum distance } \\
\text { criterion }\end{array}$ & 8.8 & 9.1 & 15.0 & 9.1 & 13.1 \\
\hline \multicolumn{6}{|l|}{ Adj't speeds: } \\
\hline Capital stock & $24 \%$ AR & $25 \%$ AR & n.a. & $24 \%$ AR & $22 \% \mathrm{AR}$ \\
\hline Investment & $34 \%$ QR & $27 \%$ QR & & $40 \% \mathrm{QR}$ & $19 \%$ QR \\
\hline
\end{tabular}

Notes: See table 1. 
Columns 2 and 3 impose two values of $\gamma_{1}, 30$ and 0 . Given the precision of the $\gamma_{1}$ estimates in column 1 , it is not surprising that imposing $\gamma_{1}=0$ leads to a significant reduction in fit. Note, however, that with this restriction, the point estimate of $\sigma$ drops by somewhat more than half and is now significantly different from one. This result indicates that while it may be difficult to obtain precise estimates of both $\gamma_{1}$ and $\sigma$, it appears that the joint hypothesis of $\gamma_{1}=0$ and $\sigma=1$ can be strongly rejected. The final two columns consider two alternative values of $\sigma, 1.0$ and 0.07 . Setting $\sigma=1$ has little effect on the fit of the model; the estimates of the adjustment cost parameters are little changed and remain strongly statistically significant. Setting $\sigma=0.07$ leads to a larger reduction in fit, and this restriction can be rejected at the 5 percent confidence level.

Figure 4 compares the impulse responses from the structural model estimates reported in column 1 of table 4 with the VAR impulse responses. With this set of parameter estimates, the structural model fits the technology shock IRF less well than the best-fitting model shown in figure 3. However, the model does a good job of capturing the effects of the monetary-policy and inflation shocks on investment.

Table 5 reports results based on matching the impulse responses of four shocks - to monetary policy, technology, inflation, and the IS curve. In table 5, the restriction $\sigma=1$ is imposed, because, left unconstrained, $\sigma$ tends toward very high values; the value of the minimum-distance criterion changes little with $\sigma=1$ imposed. In column 1 , the estimate of $\gamma_{1}$ is quite small and not significantly different from zero. In column 2, the restriction $\gamma_{1}=0$ is imposed. Neither the fit nor the coefficient estimates are much affected. In particular, $\gamma_{2}$ is 6.7 , and quite precisely estimated. Column 3 shows that moderate capital-stock adjustment costs $\left(\gamma_{1}=30\right)$ are strongly rejected. 
Figure 4

Response of Investment to Technology, Monetary-Policy, and Inflation Shocks

Comparison of VAR and Structural Model Responses

Technology shock

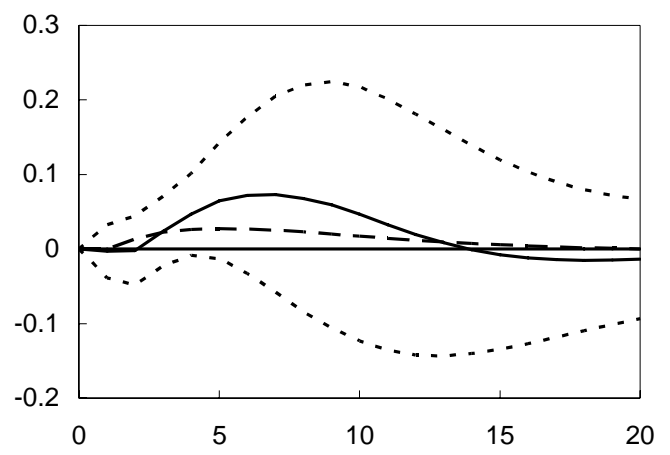

Monetary-policy shock

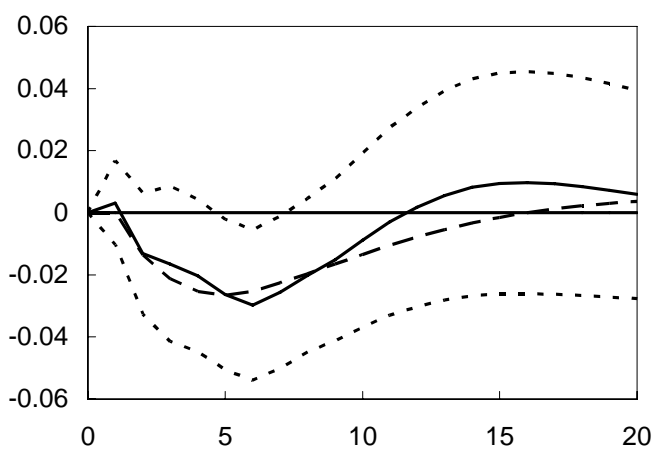

Inflation shock

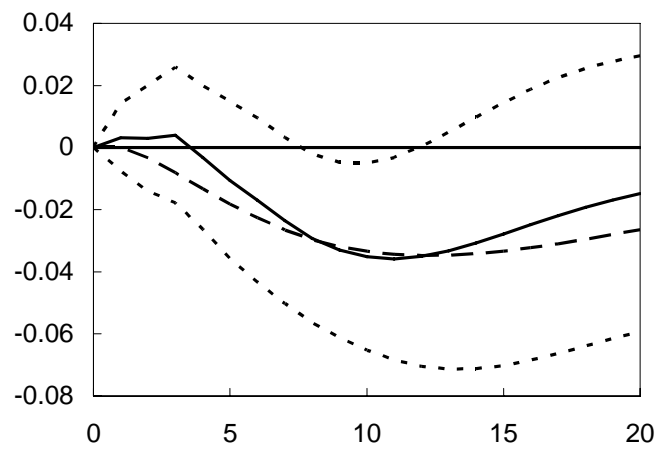

Notes: Responses to unit shocks

Solid line: VAR impulse response

Dotted: 90 percent confidence interval around VAR impulse response

Dashed: Structural model; allows $\sigma$ and investment and capital stock adjustment costs to be freely estimated 
Table 5

Estimates of Structural Investment Model

Based on matching monetary-policy, technology, inflation, and IS-curve IRFs

\begin{tabular}{lccc}
\hline & $(1)$ & $(2)$ & $(3)$ \\
\hline$\gamma_{1}$ & 1.5 & 0.0 & 30.0 \\
& $(12.1)$ & -- & -- \\
$\gamma_{2}$ & 6.7 & 6.7 & 7.7 \\
$\sigma$ & $(1.7)$ & $(1.7)$ & $(2.3)$ \\
& 1.0 & 1.0 & 1.0 \\
Minimum distance & -- & -- & -- \\
criterion & 45.5 & 45.5 & 51.5 \\
\hline
\end{tabular}

Notes: See notes to table 1.

Figure 5 shows the impulse responses from the model with the parameters shown in column 2 of table 5. The key additional piece of information relative to the structural-model impulse responses shown in figure 4 is the impulse response function from the IS shock. With this estimate of the structural parameters, the model predicts that there will be a highly persistent response of investment to the IS shock; this persistence allows the model to capture the persistent effects of this shock in the VAR. However, the structural model fails to capture the initial rise in investment following the IS shock: The responses from the estimated structural model are outside the VAR's 90 percent confidence interval in the first few quarters following the shock. This instance is the first we have seen in which the 90 percent confidence interval has been breached.

For the monetary-policy and inflation shocks, the model IRFs in figure 5 are close to the VAR impulse responses over the first eight to ten quarters. After that, however, the model simulations predict considerably more persistence in investment than in the VAR IRFs, or than in the model results shown in figure 4. This shift is likely related to the fact that $\gamma_{1}=0$ in figure 5: As we saw in figure 2, when capitalstock adjustment costs were not allowed, investment adjustment costs were high and investment was too persistent. 
Figure 5

Response of Investment to Technology, Monetary-Policy, Inflation, and IS Curve Shocks

Comparison of VAR and Structural Model Responses

Technology shock

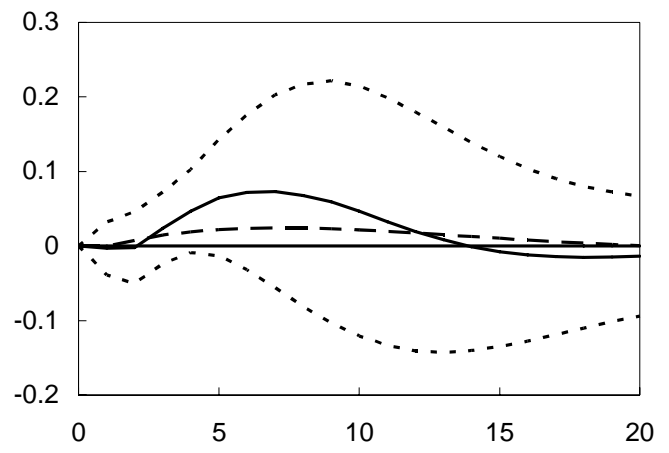

Inflation shock

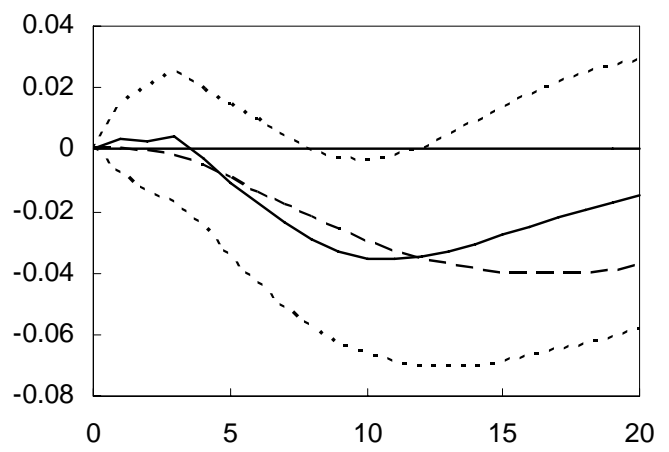

Monetary-policy shock

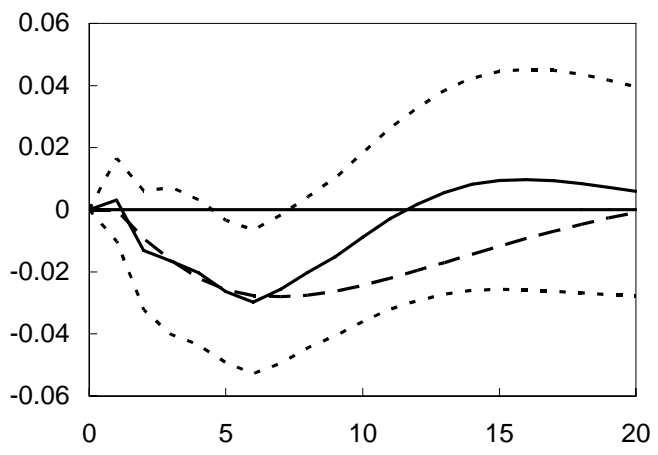

IS curve shock

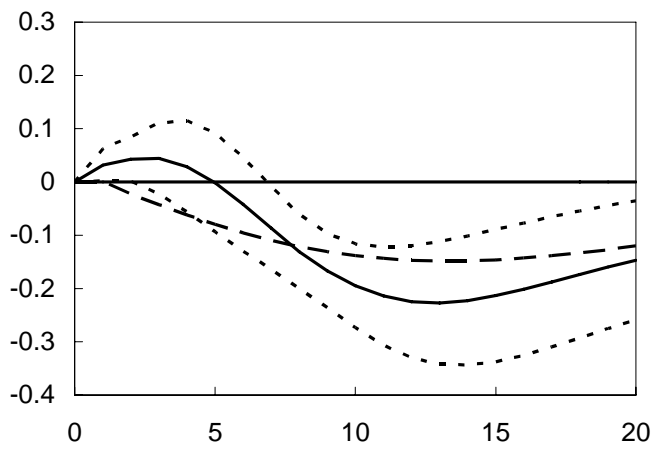

Notes: Responses to unit shocks

Solid line: VAR impulse response

Dotted: 90 percent confidence interval around VAR impulse response

Dashed: Structural model; $\sigma=1$, investment adjustment costs only

There is a possible economic explanation for the high value of $\sigma$ that is needed to take account of the effects of the IS shock. Recall from section 2 that while the IS shock leads initially to an increase in output and hours, it pushes down investment after a few quarters. Because the drop in investment is preceded by an increase in interest rates, one interpretation is that the investment drop is the result of an important crowding-out effect, whereby the increase in interest rates leads to a reduction in investment despite elevated output. Large crowding-out effects require 
that interest rates have important effects on investment and thus that $\sigma$ is large. Furthermore, the crowding-out effect in the VAR was precisely estimated, and so it has a strong influence on the estimation.

That having been said, there are reasons to be suspicious of the results based on the IS shock. As noted earlier, while the crowding-out effect appears to be large and statistically significant in the structural VAR, it has not been widely remarked upon. Before drawing strong conclusions from the implications of this shock for crowding out, we would want to confirm that it is a robust phenomenon. Moreover, the overall fit of the model is much worse in table 4 than in the earlier tables. For example, the value of the minimum distance criterion rises from about 9 from the best-fitting models in table 4 to about 45 in column 1 of table 5 . While a $\chi^{2}$ statistic of 90 is far from indicating a statistically significant rejection of the model when there are 77 degrees of freedom, these results nonetheless suggest that the parameters needed to take account of the IS shock are very different from those that best fit the responses to the other three shocks: Recall that the joint restriction $\gamma_{1}=0$ and $\sigma=1$, which seems to work best in table 5, was strongly rejected when only the responses to first three shocks were considered in table 4.

\section{Long-run and short-run evidence on the elasticity of substitution}

In the preferred estimates, the elasticity of substitution is found to be less than one. This estimate was based on matching impulse responses over twenty quarters and therefore reflects the short-run properties of investment dynamics. There is some indication, however, that the long-run properties of investment suggest a higher elasticity. In particular, the ratio of non-high-tech investment to business sector output has been fairly stable over time, which is what we would expect if the long-run elasticity of substitution were one. For example, the average share in the late 1990s (6.9 percent of business-sector output) was about the same as the average level in the 1959-2002 period. In addition to the empirical evidence, another reason to prefer a unitary long-run elasticity is its convenience in long-run modeling: An elasticity of one implies that the ratio of investment to output will be stable over time, even if 
there is a trend in the relative price of capital equipment. Stable long-run ratios make it much easier to solve for the long-run equilibrium in a model. ${ }^{4}$

How can we reconcile a small short-run elasticity of substitution with a large long-run elasticity? Roberts (2003) argues that costs to changing the capital-output ratio are one possibility. Such costs may arise because it is costly to reorganize production. Looking at evidence from individual firms, Brynjolfsson, Hitt, and Yang (2002) argue that reorganization costs can be quite substantial. Roberts (2003) finds that adding reorganization costs to a model with capital-stock and investment adjustment costs allowed the model to fit both the rapid response of investment to output shocks and the attenuated response of investment to movements in user cost, while preserving a long-run elasticity of substitution equal to one.

\section{Conclusion}

The results of this paper suggest that, in response to a key set of macroeconomic shocks, the elasticity of substitution is considerably smaller than one. Furthermore, the joint hypothesis that the elasticity is one and capital-stock adjustment costs are zero can be strongly rejected. These results also suggest that both investment- and capital-stock adjustment costs are important: The size of the capital-stock adjustment costs is in line with estimates from firm-level studies. Investment adjustment costs are statistically significant but relatively small and suggest that investment adjusts rapidly

\footnotetext{
${ }^{4}$ Whether the stability of the investment share is informative about the elasticity of substitution depends on the long-run trend in the relative price of non-high-tech investment goods: If the relative price is trending (down) over time, the stability of the nominal spending share is indicative of a unit elasticity; if the relative price is stationary, the stability of the share doesn't tell us much about the elasticity of substitution. The trend in the relative price of non-high-tech investment goods is a matter of some controversy. In the official national accounts data, there is little trend movement in these relative prices. Cummins and Violante (2002), however, have argued that the national accounts data miss a good deal of quality improvement in investment goods. They argue that adjusting for overlooked quality improvements takes about 3 percentage points per year off the average rate of price increase. In that case, there would be an important trend in the relative price of non-high-tech equipment. While it is also possible that there is upward bias in price indexes for other components of spending, Lebow and Rudd (2003), in their comprehensive survey, estimate the bias in consumer prices at only 1 percent per year; net of both adjustments, non-high-tech equipment prices would still have a substantial downward trend relative to consumer prices.
} 
to the pace determined by the capital-stock adjustment process, consistent with evidence on firms' planning lags.

Because these estimates abstract from the effects of the shock to investment itself, they are robust to reverse causation. Hence, reverse causation can be ruled out as a source of the finding of a small elasticity of substitution. There is, however, an important sensitivity to another of the shocks: When the responses to an identified IS shock are included among those to be matched, the response of investment to changes in user cost is estimated to be much stronger, implying an elasticity of substitution that is large and not significantly different from one. In this case, only the investment adjustment cost is estimated precisely; the capital stock adjustment cost parameter is estimated to be small and not significantly different from zero.

The principle that more information is better would argue for preferring the results that include the IS impulse responses. There are reasons, however, to be suspicious of these results. For one, the overall fit of the model deteriorates when the IS shock is included: The responses to the other shocks can be jointly fit quite closely, whereas fitting the IS curve as well necessitates a compromise that leads to a deterioration in the fit. Also, the strong crowding out effect of the IS shock- the apparent source of the large elasticity estimates when this shock is used-has not been widely documented. Prudence is thus called for in interpreting the results based on this shock.

An unfortunate aspect of these estimates has been the wide confidence interval around many of the impulse responses, especially for the technology shock. These wide confidence intervals limit the precision of the structural estimates. One approach that might help would be to use structural specifications for the remaining equations of the model. Recent work by Del Negro and Schorfheide (2004) suggests that, once allowance is made for the number of estimated parameters, structural models may actually dominate VARs as characterizations of the data. And because they are more sparsely parameterized, estimates from structural models are likely to be more precise. A further advantage of structural estimation would be the opportunity for verifying the empirical relevance of the IS-curve crowding-out effect. 


\section{References}

Amato, Jeffery D. and Thomas Laubach (2004) "Implications of Habit Formation for Optimal Monetary Policy," Journal of Monetary Economics 51, 305-25.

Brynnjolfsson, Eric, Loren M. Hitt, and Shinkyu Yang (2002) "Intangible Assets: Computers and Organizational Capital," Brookings Papers on Economic Activity 2002:1, 137-81.

Chirinko, Robert S. (1993) "Business Fixed Investment Spending: Modeling Strategies, Empirical Results, and Policy Implications," Journal of Economic Literature 31, 1875-911.

, Steven M. Fazzari, and Andrew P. Meyer (1999) "How Response Is Business Capital Formation to Its User Cost? An Exploration with Micro Data," Journal of Public Economics 74, 53-80. , and (2005) "That Elusive Elasticity: A Long-Panel Approach to Estimating the Capital-labor Substitution Elasticity," working paper, Washington University (St. Louis; September).

Christiano, Lawrence J., Martin Eichenbaum, and Charles L. Evans (2005) "Nominal Rigidities and the Dynamic Effects of a Shock to Monetary Policy," Journal of Political Economy 113, 1-45. , and (1999) "Monetary Policy Shocks: What Have We Learned and to What End?" in John B. Taylor and Michael Woodford, eds., Handbook of Macroeconomics, Volume 1a, Elsevier Science, North-Holland, 65-148.

, and Robert Vigfusson (2005) "Assessing Structural VARs," Board of Governors of the Federal Reserve System, manuscript (May).

Cummins, Jason G., Kevin A. Hassett, and Stephen D. Oliner (1999) "Investment Behavior, Observable Expectations, and Internal Funds," Board of Governors of the Federal Reserve System, Finance and Economics Discussion Series, no. 1999-27.

and Giovanni L. Violante (2002) "Investment-Specific Technical Change in the United States (1947-2000): Measurement and Macroeconomic Consequences," Review of Economic Dynamics 5, 243-84. 
Del Negro, Marco and Frank Schorfheide (2004) "Priors from General Equilibrium Models for VARs," International Economic Review 45, 643-73.

Edge, Rochelle M. (2000) "Time-to-Build, Time-to-Plan, Habit-Persistence, and the Liquidity Effect," Board of Governors of the Federal Reserve System, International Finance Discussion Papers, no. 673.

Gilchrist, Simon and Charles P. Himmelberg (1995) "Evidence on the Role of Cash Flow for Investment," Journal of Monetary Economics 36, 541-72.

and (1998) "Investment: Fundamentals and Finance," NBER Macroeconomics Annual 1998, 223-73.

Hayashi, Fumio (1982) “Tobin's Marginal $q$ and Average $q$ : A Neoclassical Interpretation," Econometrica 50, 213-24.

Lebow, David E. and Jeremy B. Rudd (2003) "Measurement Error in the Consumer Price Index: Where Do We Stand?” Journal of Economic Literature 41, 159-201.

Lucas, Robert E. (1967) "Adjustment Costs and the Theory of Supply," Journal of Political Economy 75, 321-34.

Roberts, John M. (2003) "Modeling Aggregate Investment: A Fundamentalist Approach," Board of Governors of the Federal Reserve System, Finance and Economics Discussion Series, no. 2003-48.

(2001) "Estimates of the Productivity Trend Using Time-Varying Parameter Techniques," Contributions to Macroeconomics 1, issue 1, article 3.

Rotemberg, Julio J. and Michael Woodford (1997) "An Optimization-Based Econometric Framework for the Evaluation of Monetary Policy," NBER Macroeconomics Annual 1997, 297-346.

Shapiro, Matthew D. and Mark W. Watson (1989) "Sources of Business Cycle Fluctuations," NBER Macroeconomics Annual 1989.

Tevlin, Stacey and Karl Whelan (2003) "Explaining the Investment Boom of the 1990s," Journal of Money, Credit, and Banking 35, 1-22. 